cristalina en las sombras de la que habló Camón Aznar en relación a la Inmaculada de la iglesia de la Compañía ${ }^{19}$, datable también en los últimos años del autor. No obstante, debemos tener en cuenta que la calidad técnica de alguno de sus seguidores, sobre todo Nicolás Borrás, no nos permite afirmar con rotundidad la autoría de Juanes, si bien nos inclinamos por ella.

Todo ello nos hace pensar, que esta obra fue pintada por Juan de Juanes en la última época de su vida, quizá entre 1570 y 1575.

En los fondos Fotográficos del Servicio Nacional de Recuperación Artísticoa que se guardan en el Departamento "Diego Velázquez" del C.S.I.C., existe la fotografía de un cuadro que representa también el Rostro de la Virgen. Es una tabla distinta a las versiones de Valencia y de Atienza, ya que no tiene nimbo como éstas. Por lo que se puede apreciar a través de la fotografía, parece una obra de taller, a causa de la mayor dureza de los rasgos y de la menor delicadeza de las sombras, o bien una copia de un artista poco dotado; lo que no sería de extrañar dado el éxito popular de las obras de Juan de Juanes. El rostro es más alargado, los ojos están un poco más cerrados y la barbilla se marca en exceso. No obstante es una copia fiel de la obra de Juanes e imita con escrupulosidad casi todos los pliegues del ropaje por lo que quizá tuvo delante el original del maestro (Fig. 10).

F. Javier RAMOs GÓMEZ Becario Universidad Autónoma

\title{
NOTICIAS DOCUMENTALES SOBRE MORO ¿O KEY? Y SOBRE EL CARAVAGGIO
}

Los especialistas de la pintura flamenca del siglo xvi conocen bien los magníficos retratos de Antonio del Río, Señor de Cleydael y de Aertselaer, y el de su esposa Leonor López de Villanueva, conservados en el museo del Louvre. Se presumía su procedencia española pues procedían de la colección del General Conde de Armagnac, reunida en su mayoría en España. Se ha destacado la personalidad del retratado, acompañado de sus hijos, uno de los cuales, Martín Antonio, fue famoso teólogo jesuita, y la de su esposa pero se ha discutido su clasificación. Algunos autores, como Friedländer e Hymans, los atribuyeron a Antonio Moro pero posteriormente el Catálogo del Museo del Louvre los consideró obra de Willem Key (Figs. 11 y 12) ${ }^{1}$.

Se ha localizado ahora la procedencia exacta de estos retratos y su pertenencia a un tríptico de mayores dimensiones. Aunque la noticia no desvela el nombre de su autor, quizás apunta más hacia Moro.

En los documentos que el Archivo Histórico Nacional conserva del Convento de la Trinidad de Burgos, se localizaron referencias sobre la Capilla de la Resurrección, dotada por Jerónimo del Río, casado con Clara Manrique de Lara, de la familia protectora de este convento. Entre los papeles se incluye el testamento de Antonio del Río, natural de Lisboa y que había redactado el documento en esta ciudad el año de 1584, fecha que no coincide con la de 1582 que aparece en otra referencia ${ }^{2}$.

19 Camón Aznar, J.: Summa Artis. Pintura del siglo xvi, tomo XIV, Madrid, 1978, pp. 92-100.

1 Hymans, H.: Antonio Moro. Son oeuvre et son temps, Bruxelles, 1910, págs. 146-148, láms. 43-44. Miden 1,66 x 0.80 m. Friedländer, M.: Die altniederländische Malerei Antohonis Mor and seine Zeitgenossen, Leiden, 1936, vol. Xlll. La Peinture du Musée du Louvre. T. II. Les écoles étrangères. Publié sous la direction de Jean Guiffrey, Paris, 1941, láms. 43-44, pág. 44 (bajo el nombre de Key). Jordan, A. M.: Retrato de Corte en PortugaL O Legado de Antonio Moro (1552-1572), Lisboa, Querzal, edit. 1994.

2 Archivo Histórico Nacional (AHN). Sección de Clero, Burgos, Trinitarios. Legajo 1017. 
El otorgante es hermano de Jerónimo al que lega dinero para su capilla de la Resurrección y declara:

"Que en la iglesia de Aertselaer yo abia puesto un retablo de la avocacion del Espirita Santo... muy grande y en la tabla en medio tiene la vocación del Espirita Santo y en las puertas en la una estoy yo e mis hijos retratados al bibo con la bocación de la Santissima rresurrección y en la otra esta retratada al bibo dona Leonor lopez de villanoba mi amada mujer con la bocacion de la Acencion de nuestro señor... y por quanto en la destruycion de la dha yglesia me salbaron dho rretablo e me le embyan aqui a Lisboa donde al presente le tengo enpacado en quatro caxas y por quel dho rretablo es de muy excelente mano e dino de ser guardado e que me costo muchos dineros mando se envie a Burgos y que mi heredero lo ponga en la capilla de la Resurrección».

El convento burgalés de la Trinidad fue arrasado por los franceses en la Guerra de la Independencia pero al parecer salvando las obras de arte que les interesaron. El General Darmagnac, de cuya colección procedía el cuadro del Louvre, estuvo al mando de la guarnición francesa que ocupó la ciudad de Burgos ${ }^{3}$.

Ponz vio el tríptico en el claustro del citado convento de los Trinitarios de Burgos con una tabla central de:

«La Venida del Espíritu Santo, tiene sus puertas con retratos de personas arrodillados todo ejecutado grandemente en el estilo flamenco y en un letrero que debajo se lee dice que le mando hacer a su costa Antonio del Río Señor de Cleidale y de Aertselaer cerca de Amberes, del Consejo de Hacienda de Carlos II (sic). Es obra de mucho mérito especialmente en la parte de los retratos".

Aunque no dio el nombre de su autor supo valorar su maestría de pintor flamenco pero su texto, ajustado muy literalmente al del documento, no menciona las advocaciones de la Resurrección y de la Ascensión y equivoca, quizás error de imprenta, el nombre del soberano bajo el que sirvió Antonio del Río ${ }^{4}$.

No se conoce el destino de la tabla central que representaba la Venida del Espíritu Santo y no se entiende bien las referencias a las advocaciones de la Resurrección y de la Ascensión que al parecer presidían los retratos del donante y de su esposa. Puede ser que estén representadas en los fondos de las tablas, bastante oscurecidos, o en su reverso, pero no se refieren a ello los historiadores que estudiaron los cuadros. Los datos ahora conocidos pueden facilitar la localización de la tabla central y la reconstrucción de lo que fuera en su día un gran tríptico que decoró primero la iglesiade Aertselaer y años más tarde la del convento de la Trinidad de Burgos.

Hace algunos años revisando documentos en el Archivo Histórico Nacional sobre el desaparecido convento de Santo Domingo el Real de Madrid, localizamos un testamento de un personaje de la Corte en el que se relacionaban una serie de importantes pinturas que legaba a familiares y amigos, por los apellidos, españoles. Los datos pueden ser de interés para los especialistas por lo que en breve síntesis los exponemos a continuación.

El testamento de D. Francisco de Córdoba instituía una serie de capellanías en dicho convento de Santo Domingo, en la capilla de los Córdoba «que llaman de los Castilla». El documen-

3 Huidobro de la Serna, L.: Convento de la santísima Trinidad de Burgos. Capilla y sepulcros de los Medina. Puerta de la Antigua Iglesia. Boletín de la Sociedad Castellana de Excursiones, 1907-1908, pág. 439, y 1090-1910, págs. 393-393. García Ramila, L.: Del Burgos de Antaño. Dos testamentos de Alonso de Astudillo Mazuelo, el fundador del Colegio y Capilla de San lldefonso en el desaparecido Monasterio de la Trinidad, Boletín de la Institución Fernán González, 1952, págs. 307-332. Estella, M.: Obras escultóricas del siglo xvi en los Conventos de la Trinidad y de la Merced en Burgos $A r-$ chivo Español del Arte, LII, n. ${ }^{\circ}$ 205, 1979, pág. 55-73. Aguado Bleye, P.: Manual de Historia de España, t. II, Edad Moderna 4. ${ }^{a}$ ed. Bilbao, 1925, pág. 440, sobre Darmagnac.

4 Ponz, A.: Viaje de España seguido de dos tomos del Viaje Fuera de España 1772-1794 Preparación, Casto María del Rivero, Madrid, Aguilar, 1947, pág. 1.053, n. ${ }^{\circ} 28$. 
to se había redactado en Palermo el 25 de enero de 1625 ante el Juez Alonso Alphaxano ¿?, escribano de la Armada Real, que abrió ante Lorenzo de Monterroso, escribano de ella el 3 de enero de 1631. Su traslado al Convento se realiza años más tarde 5 .

Francisco Fernández de Córdoba, Caballero de Calatrava, Comendador en Carrión, gentilhombre de la Boca de Sus Majestades Felipe III y Felipe IV, había sido Caballero Mayor de Emmanuel Filiberto de Saboya, Virrey de Sicilia y Generalísimo de la Mar, y era hijo de D. Francisco Fernández de Córdoba, Marqués del Carpio y de D. ${ }^{a}$ Luisa Mexia de Avendaño, según se indica en el testamento.

Dispone su enterramiento en el convento de Santo Domingo y como es usual encarga misas por su alma.

Entre sus mandas materiales de interés artístico destaca el encargo a sus testamentarios de hacer un cáliz y una patena de plata para el convento de Calatrava y una lámpara de plata para la iglesia de Carrión. A su tía D. ${ }^{a}$ Ana María, dueña de honor de la Reina, le envía un Cristo de marfil que le regaló Urbano VIII y dos cuadros, el de la Adoración de los Reyes de Alberto Durero y el del Esponsalicio de Santa Catalina con el Niño. Recuerda el «amor y buena voluntad" que le ha tenido y le pide "lo convierta en favor, y merced a $D .^{a}$ Luisa Mexia de Abendaño» su madre, pues "faltándole» él, "le a de faltar el abrigo y sustento de la vida» por lo que ruega a Su Majestad «una pensión equibaiente con que pueda sustentar mi Madre los días de su vida pues de mí no queda otro heredero que lo pueda pretender».

A D. Juan de ¿Xérica? Iega el cuadro del Bautismo del Señor para el monasterio que había fundado, a D. Francisco Manuel, Caballero de Calatrava, El Sacrificio de Abrahám y a D. Juan Rivero de Vargas, Caballero de Santiago, el cuadro de Nuestro Sr. quando le quieren poner en el Sepulcro. A continuación deja en su testamento al P. Gaspar de Avendaño, hermano de su madre, un San Francisco y un San Pedro, medianos, un San Juan sobre piedra, una Cabeza de Cristo, pequeño, y una cruz de acero con reliquias.

La referencia al Caravaggio aparece después, cuando lega a Gaspar de la Sal, «Veedor y Contador mayor de la Caballeria de su Alteza», el cuadro de "San Jerónimo de Caravacho» (sic) y a Juan de Acosta, Mayordomo del Estado "un quadro de San Juan con el Cordero del Caravacho" recordando el afecto que le tuvieron.

Se menciona a continuación el Inventario de sus bienes, joyas, ropa y pintura que se venderían en pública almoneda, dejando como heredera a su madre D. ${ }^{a}$ Luisa y aclarando que su Alteza, posiblemente refiriéndose a Filiberto de Saboya, le regaló un cuadro de la Resurrección de Lázaro que vino de Roma. También reclama la parte de la herencia del Marqués del Carpio y de las casas de su madre en Alcalá de Henares, de los Mejia. Entre sus familiares menciona a su tío Diego Fernández de Córdoba, Deán de Sevilla y recuerda a los enterrados en Santo Domingo el Real, Diego Fernández de Córdoba, Comendador de Calatrava y Caballero de Felipe II y D. ${ }^{\text {a }}$ Ana María Lasso de Castilla, sus abuelos, el citado Deán de Sevilla y D. ${ }^{a}$ Catalina Fernández de Córdoba, Condesa de Paredes.

Manda que una cruz de oro con reliquias que fue de Don Filiberto se entregue a D. ${ }^{\mathrm{a}}$ Margarita, Princesa de Mantua por que fue de su hermano y nombra como sus testamentarios a su tía D. ${ }^{a}$ Ana María Fernández de Córdoba, a su madre, D. ${ }^{a}$ Luisa Mexia de Avendaño, a D. Juan de ¿Xérica?, a D. Francisco Manuel, a D. Juan de Rivero Vargas, a Gaspar de Avendaño, su tío y a su primo Claudio del Castillo y Carvajal, a D. Gaspar de la Sal, a Juan de Acosta y a Francisco Ordóñez, casi todos ellos mencionados en sus mandas.

\footnotetext{
5 AHN: Sección de Clero, Madrid, Santo Domingo el Real. Legajo 3.908. Se mencionó la existencia del testamento sin especificar su contenido, en Estella, Margarita. El Convento de Santo Domingo el Real de Madrid. Villa de Madrid. XVI, 1978, II, 59-67, 67, nota 3. Idem. Los artistas de las obras realizadas en Santo Domingo el Real y otros monumentos madrileños de la primera mitad del siglo xvı. Anales del Instituto de Estudios madrileños, 1980, pág. 5, nota 10.
} 


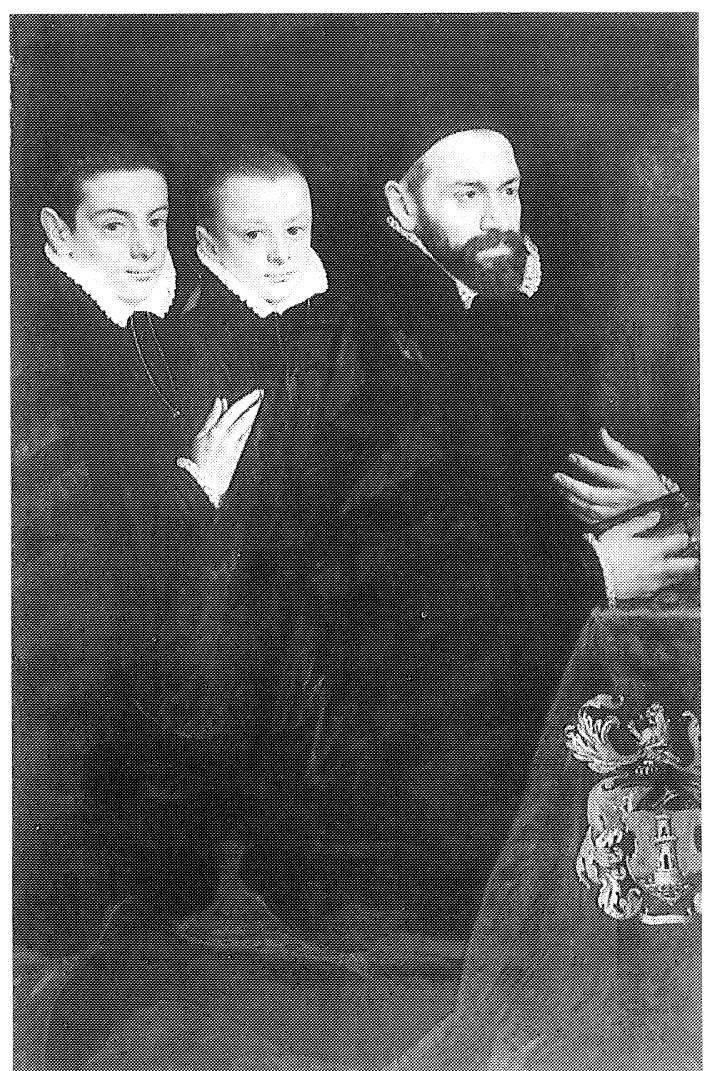

11

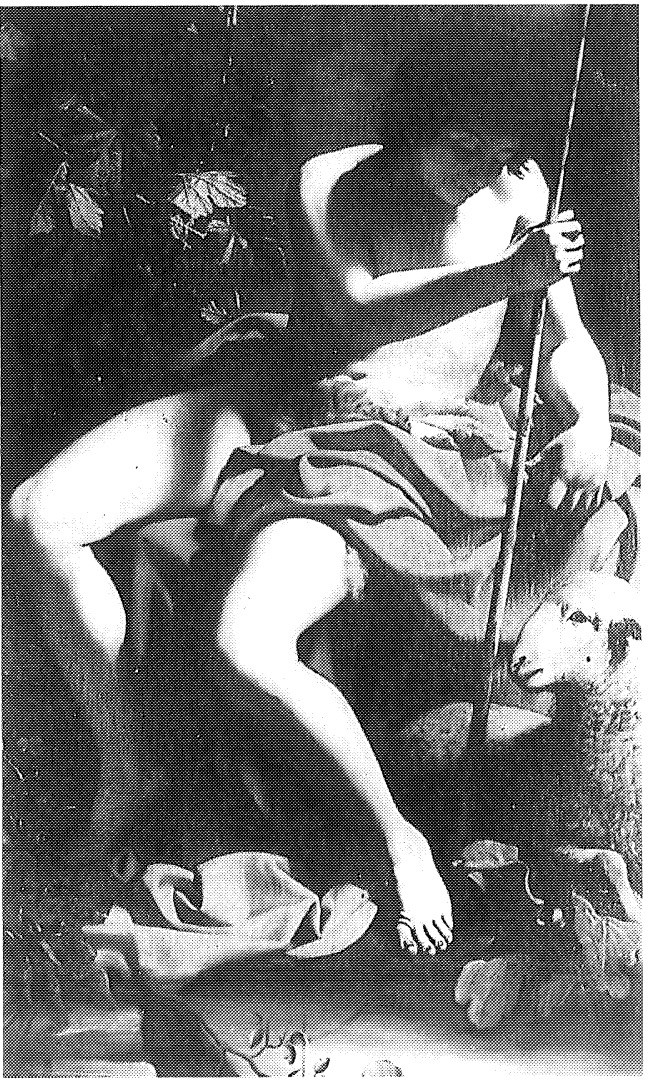

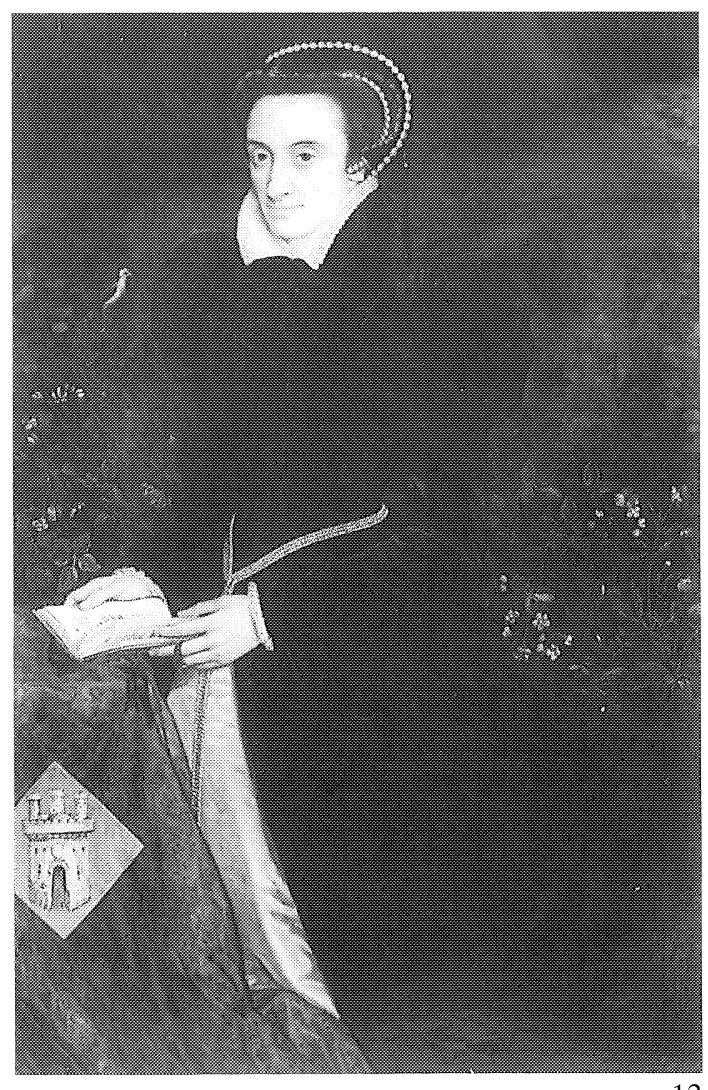

12

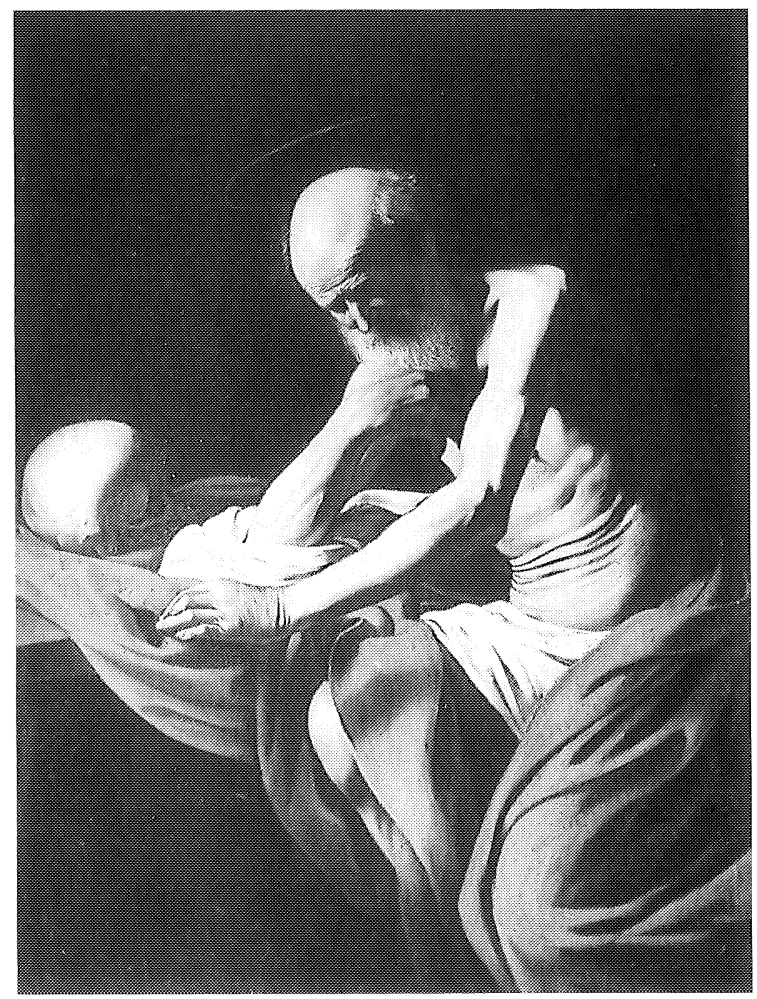

Figs. 11 y 12. A. Moro o ¿W. Key? Don Antonio del Rio Señor de Cleydael y Aertselaer, con sus hijos y su esposa D. ${ }^{a}$ Leonor López de Villalobos. París. Museo del Louvre.

Fig. 13. Caravaggio, (atrib. a). San Juan Bautista, Toledo Catedral.

Fig. 14. Caravaggio, (atrib. a). San Jerónimo, Abadía de Montserrat. 
Se ha dado la enojosa lista de nombres porque ayudaron a la identificación del otorgante, al parecer hijo ilegítimo de D. Francisco Fernández de Córdoba, 5. ${ }^{\circ}$ Señor de Armuña, casado con D. ${ }^{a}$ María Díaz de Haro y Sotomayor, 2. ${ }^{a}$ Marquesa del Carpio, título que hereda el hijo de ambos, D. Diego Luis Fernández de Córdoba, 3.er Marqués del Carpio, casado con D. ${ }^{a}$ Juana Sandoval. Las fuentes sobre Genealogía y Heráldica repiten los nombres citados a excepción del de D. Luis Mexia de Avendaño, la madre 6.

Respecto a la localización de las obras artísticas mencionadas en el testamento no se intentó la de aquellas que como el Cristo de marfil 7 resultaría inútil, ni la de los cuadros de los que sólo se describe el asunto aunque pudiera ayudar en algún caso las circunstancias que acompañaron a la donación, como las referentes al de la Resurrección de Lázaro. La búsqueda de una posible lámpara de plata de Carrión no dio resultado ${ }^{8}$ y la identificación de la Adoración de los Reyes de Durero, tampoco se intentó pues es bien sabido la usual atribución a este artista de miles de cuadros de caracteres flamencos.

Presenta mucho más interés la búsqueda de las obras del Caravaggio que pudieron llegar a España y de las que por las fechas del artista y del donante, posible acompañante del entonces Virrey de Sicilia en escenarios de la vida del Merisi, no parece pueda dudarse de su autenticidad ${ }^{9}$. El Profesor Pérez Sánchez ha aludido a la escasez de documentos sobre el envío de obras del pintor a España ${ }^{10}$ a lo que se refiere un anterior estudio de Ainaud de Lasarte ${ }^{11}$. Por ello creemos que los datos dados en el testamento podrían ayudar al especialista en su localización aunque presenten muchos puntos a resolver, como la personalidad de los beneficiarios de las obras del Caravaggio.

Una de ellas podría ser el famoso San Juan Bautista (Fig. 13) de la Catedral de Toledo del que sólo sabemos fue un regalo del Vicario General realizado en 1786 dándose la circunstancia que los patrones de las capellanías fundadas por el otorgante del testamento de Santo Domingo el Real de Madrid, eran el Sr. Vicario de Madrid y el Prior del Convento aunque se desconoce si el cargo de Sr. Vicario General y de Madrid pueden homologarse 12.

No podemos sugerir nada respecto al magnífico San Jerónimo (Fig. 14) de la Abadía de Montserrat pues no llegó a España hasta el año 1917 pero si podemos imaginar que quizás es obra similar a la que en su día el otorgante del comentado testamento lega a D. Juan de Acosta ${ }^{13}$.

\section{Margarita EsTELLA

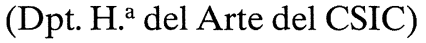

\footnotetext{
${ }^{6}$ García Carrafa, A. y A.: Enciclopedia Heráldica y Genealógica hispano-americana, t. 34, Madrid, 1929, págs. 25-26: 7. a rama de la Casa Mayor de Córdoba. T. 40, Madrid, 1931, págs. 289-290: Casa de Haro, Marqueses del Carpio.

7 Estella Marcos, M. M.: La escultura barroca de marfil en España. Las escuelas europeas y las coloniales. Madrid, CSIC, 1984, 2 vols. Catálogo, II, n. ${ }^{\circ}$ 93, recuerda la pieza.

8 Navarro García, R.: Catálogo Monumental de la Provincia de Palencia, II, Palencia, 1932: de las siete iglesias de Carrión, ninguna conserva, según el Catálogo, una lámpara de plata Inventario artístico de Palencia y su providencia, II, Madrid, 1980: se revisó también.

9 Hibbard, H.: Caravaggio, Londres, Thames and Hudson, 1988 (1. ${ }^{a}$ ed. 1983), pág. 320: sobre el San Juan de Toledo y el San Jerónimo de Montserrat. Marini, Maurizio, Caravaggio, Michelangelo Merisi da Caravaggio «pictor praestantissimus», Roma, 1989, 2. ${ }^{a}$ ed., n. ${ }^{\circ}$ 60, el San Jerónimo de Monserrat. No recoge el S. Juan Bautista de Toledo.

10 Pérez Sánchez, A. E.: Caravaggio y el Naturalismo español, Sevilla, Reales Alcázares, septiembre-octubre, 1973.

11 Ainaud de Lasarte, J. R. y C.: Anales y Boletín de los Museos de Barcelona, 1947, págs. 345-414. Menciona entre otros, el dato recogido por Bellori sobre la relación del Caravaggio con el Conde de Benavente.

12 Ponz, cit. pág.133. Lo atribuye a Caravaggio y especifica que fue regalo del Canónigo Santamaría. Parro, S.: Toledo en la mano, Toledo, 1857, pág, 316, también lo considera obra del Caravaggio. Ainauid, cit. pág. 388, n. ${ }^{\circ} 23:$ Recuerda que se le añadió una franja para hacer pareja con el San Bartolomé de Maella precisamente en 1786. Rivero Recio, J. F.: Guía de la Catedral del Toledo, 1949, pág. 144, fig. 142, proporciona el dato de su donación en 1786 por el Vicario General, que no sabemos si puede indentificarse con el Canónigo Santamaría citado por Ponz en aproximadamente la misma fecha.

13 Ainaud, cit. pág. 395, n. ${ }^{\circ}$ 33. Recuerda el San Jerónimo de Montserrat y su fecha de la adquisición en Roma el año de 1917.
} 